\title{
Is there a universal right to higher education?
}

\author{
Tristan McCowan (University College London) \\ Published in British Journal of Educational Studies (2012), 60 (2), pp. 111-128.
}

\begin{abstract}
Opposition to university fees is often framed as a defence of higher education as a 'right' rather than a 'privilege'. However, the basis and nature of this right is unclear. This article presents a conceptual exploration of the question, drawing on an initial analysis of international law. An argument is put forward for a right to higher education seen as one of a number of possible forms of post-school education, restricted only by a requirement for a minimum level of academic preparation.
\end{abstract}

\section{Keywords}

Access to higher education; higher education policy; human rights; right to education; widening participation

\section{Introduction}

The protests surrounding the recent reforms to higher education (HE) in the UK - and the associated media debate - are underpinned by the central question of whether access to university is a right or a privilege. While often reduced to the matter of fee levels, the reforms have deeper implications in terms of reframing HE study as a predominantly private good leading to an economic return, and for which individuals should consequently bear the cost. Defenders of free higher education, in contrast, argue that higher education is a public good and that it should be a universal entitlement in the same way as primary and secondary education.

Enrolment in higher education has increased rapidly over the past half century, rising to a total of 150 million students worldwide in 2007 (Altbach et al. 2009). Yet net rates of access remain low in the majority of countries - while the global enrolment rate is $26 \%$, lowincome countries enrol an average of $7 \%$ of the age cohort - with significant numbers unable to obtain a place. Given the considerable resource implications for states, the question of whether higher education study can be justifiably restricted to a few or should be made generally available becomes of paramount importance worldwide. This article assesses the validity of claims that access to higher education might be a right, and explores the nature and scope of such a right. This form of clarification is particularly important in light of the conceptual vagueness characterising current debates on the topic. 
In some high-income countries, higher education has expanded to the extent that there are almost universal opportunities for this level of study, whether or not it is considered a right and enshrined in law. However, this article does not aim to assess the extent to which higher education in this way is, or is becoming, a de facto right in the UK (or any other country). Its task is a normative, in debating whether or not we are justified in asserting a right to higher education. Establishing the validity of a moral right is of fundamental importance since it affects our positionings on questions relating to conditions of access, institutional diversity, investment of resources and the nature of provision.

Discussions of the justifications for the right to education are highly complex. First, there is the notion of 'right' itself, how this is distinct from a 'good' and the implications for individuals and society. Compounding these difficulties is the fact that the task of deciding whether education is a right depends on what is meant by 'education', and the latter is far from a unitary concept. A particular complexity of education is that it has a range of different benefits: intrinsic, instrumental and 'positional' - i.e. one's opportunities relative to those of others in society (Unterhalter \& Brighouse 2007). Justifications for the general right to education have been discussed at length elsewhere (e.g. Curren 2009; Haydon 1977; Snook \& Lankshear 1979; Wringe 1986), so for this reason and for lack of space will only be reviewed briefly here. This article will for the most part assume - as is generally accepted in national law - that all people have a right to elementary education, and assess if this right should extend to higher education.

The article will focus primarily on the question of access to higher education, rather than broader issues of justice in universities' relations to current students and the wider society, as explored in Brighouse (forthcoming), for example. In Brennan and Naidoo's (2008) terms, therefore, it focuses on the 'import' rather than the 'export' role in relation to social justice although, as the authors emphasise, the two are strongly linked. In terms of what is meant by 'higher education', there are some challenges in providing a satisfactory definition. It is hard to disentangle the concept of higher education from the particular conceptions or normative visions put forward by theorists, or from the specific models appearing at different points in history in different parts of the world. In a descriptive sense, higher education today refers to a range of institutions, most important of which is the 'university', but including other forms of college with distinct characteristics ${ }^{1}$. In recent years there has also been a proliferation of different forms of course making it hard to establish a criterion in relation to subject area.

Nevertheless, some conceptual boundaries must be placed on the notion of higher education. We would not, for example, call a short beginner's course in Spanish 'higher education', even if it were for people who had completed their school education. The first necessary aspect of higher education is that it depends on earlier study, in that students entering higher education are building on substantial previous learning (normally through schooling, though not necessarily). For that reason, higher education is normally undertaken by adults. The second necessary aspect is that it involves in-depth and sustained study. Normally it would involve specialisation into a particular area of knowledge, although a breadth of subjects is also possible, particularly in the early stages. We might like to add to

\footnotetext{
${ }^{1}$ In discussing access, this article will at times refer to 'higher education' and at times to 'university', but without denoting a specific technical distinction between them.
} 
this condition that higher education should be "emancipatory" (Barnett 1990), a "conversation" (Oakeshott 1989) or that it be "rationally defensible" (Maclntyre 1990). However, despite the desirability of these conditions, we could not exclude from the concept of higher education examples that did not always display these characteristics.

A final point is that the question of whether higher education is a right should not be identified entirely with that of whether it should be state-funded. There are a number of aspects of the university - including research and public engagement - that might justify state funding even if higher education study were not considered to be a right. Likewise, although a debatable point, there might be circumstances in which some fees might be charged even if higher education is considered a right - as long as they did not represent an impediment to access.

\section{Legal and moral bases}

Rights are justified claims that individuals (and sometimes groups) can make on others. In this article, rights are considered not in relation to particular national jurisdictions, but in their universal sense, as they relate to all human beings. This article follows Amartya Sen and others in viewing human rights primarily as moral, rather than receiving their legitimacy from legal formulations:

Human rights can be seen as primarily ethical demands. They are not principally 'legal', 'proto-legal' or 'ideal-legal' commands. Even though human rights can, and often do, inspire legislation, this is a further fact, rather than a constitutive characteristic of human rights. (Sen 2004:390)

Furthermore, he sees them as emerging from collective discussions, with their plausibility "dependent on their ability to survive and flourish when they encounter unobstructed discussion and scrutiny" (Sen 2005: 160). Normative debate on the subject of rights -without being constrained by current legal formulations -- is, therefore, not only possible but essential to the establishment and legitimisation of rights.

The purpose of this article is not, therefore, to analyse the content of the right to higher education as it exists in international law. Nevertheless, a brief look at its formulation in law will be helpful in relation to later discussions. Higher education has appeared as part of the general right to education since the 1948 Universal Declaration of Human Rights (UDHR), and in subsequent legally binding instruments such as the International Covenant on Economic, Social and Cultural Rights (ICESCR) of 1966, and the Convention on the Rights of the Child (CRC) of 1989. Article 26 of the UDHR states that, "higher education shall be equally accessible to all on the basis of merit". When taken in the context of the guarantees earlier in the Article about compulsory and free-of-charge elementary education, the notable element here is that there is no mention of the level of overall access for the population. The right guarantees that higher education be accessible, but not generally available (Beiter 2006: 97). The requirement put forward -- a very important one -- is that no one should be barred from higher education for any reason other than 'merit', i.e. not through financial disadvantage etc. However, it is possible to successfully apply this 
condition to a university system that had places for only $1 \%$ of the population -- and with a very large number of people competing for a small number of places. It is, therefore, essential to consider the procedural requirement for fair access along with attention to the total number of places available (McCowan 2004; 2007). (As will be discussed below, this does not necessarily require access for the whole population.) In this respect, the Charter of the Organization of American States of 1948 represents a significant improvement, stating that "Higher education shall be available to all, provided that, in order to maintain its high level, the corresponding regulatory or academic standards are met." The condition for particular academic standards raised here - understood as a minimum requirement - is preferable to a competition for a fixed number of places - as will be discussed in the sections that follow.

Some developments in the expression of the right to higher education can be observed in the Convention against Discrimination in Education (1960) with its undertaking to "make higher education equally accessible to all on the basis of individual capacity", and in the ICESC, which states that, "Higher education shall be made equally accessible to all, on the basis of capacity, by every appropriate means, and in particular by the progressive introduction of free education". 'Capacity' is distinct from 'merit' in that it relates to future potential rather than "students' past academic achievements" (Beiter 2006: 97), and therefore is clearly a step forward in terms of facilitating access for students from disadvantaged backgrounds who may have had poor quality previous schooling. There is also in the ICESC an (albeit tentative) mention of free-of-charge provision. However, the later CRC removes the clause about free provision, requiring states to "Make higher education accessible to all on the basis of capacity by every appropriate means". In fact, the practice of national governments has not indicated a movement towards introduction of higher education that is free at the point of delivery: quite the opposite in fact, as in the UK, there has been a tendency in many countries towards the charging of fees even in public institutions. These have been introduced on the basis of the costs of expanding access to higher education, constraints on public funds and the disproportionately privileged backgrounds of the majority of HE students and their consequent ability to fund themselves. As stated above, it is not absolutely impossible for a right to carry some financial charge, if not an impediment to access - although the fee levels in public and private universities in many countries certainly go beyond this, and undermine the universal entitlement. Student loans can mitigate the negative effects of fees, but do not completely remove them, and even in countries in which they are generally available, can still represent a disproportionate disincentive to students from low-income backgrounds on account of fear of debt or lack of confidence in the benefits of higher education study (Altbach et al. 2009). Differential fee levels (relating to differences of quality or prestige) also undermine the requirement for access on the basis of merit or capacity.

The right to higher education in international law, therefore, is partially deficient in its formulation since in determining a possible right, attention must be paid not only to procedural aspects of access to those places available, but also of the extent of availability of provision. Furthermore, even the limited requirements have not been met in the majority of states. 


\section{Justifications for the general right to education}

Before assessing the detail of the nature and scope of the right to higher education, however, it is first necessary to consider whether it is valid to speak of such a right at all. Discussions of the basis of the right to education have focused primarily on children, and on access to school. Justifications have been put forward on a variety of grounds. In his review of international law on the right to education, Hodgson (1998) outlines four justifications for the right: the social utilitarian or public interest perspective -- based on education's role in supporting democracy, world peace and preservation of community culture; a prerequisite to individual dignity -- through the imparting of essential skills and of abilities for reasoned analysis allowing for a dignified life in society; prerequisite to individual development -providing the opportunity for individuals to realise their potential; and finally, the individual welfare perspective, given that in current societies individuals without education struggle to ensure their basic needs.

Haydon (1977), on the other hand, distinguishes between three possible bases for the right. The first of these is socialisation, the acquisition of the basic capacities for functioning in a society, including language and other abilities necessary to live together with others. This is considered to be a right as it is needed in order to have a genuinely human life. The second - termed optional education - refers to the development of intellectual capacities associated with liberal education, and with the idea of the 'educated person' put forward by Richard Peters and Paul Hirst. While Haydon considers that there might be a noninterference right possible here (i.e. that people should be 'left alone' to pursue their own intellectual development), people do not have the right to call on the time and resources of others for this purpose, as it is a luxury and not 'necessary' for functioning in society. Of relevance to this article, he considers this form of education particularly unnecessary 'at the higher levels' (though not necessarily undesirable). The third form - autonomy - is located between the first and second, in that it is more extensive than socialisation, but does not move into the terrain of luxury. According to this view, we have a right to be autonomous beings, but need the assistance of others in achieving it. Basic education is a right, therefore, as it is essential to autonomy:

[S]ome degree of diversity of cognitive development is a condition of rational choice: there must be at least some awareness of alternatives between which one might choose, and some notion of criteria by which alternatives can be assessed. (p.241)

For Haydon, therefore, the right is justified through the immportance of socialisation and autonomy for living a fully human life. Curren (2009), focusing primarily on children, departs somewhat from this position in defending the right to education understood as "initiation into practices that express human flourishing" (p.52), a conception broader than the emphasis on the forms of knowledge of Peters and Hirst.

However, rather than the above perspectives based on the intrinsic value of education, arguments most often focus on education's instrumental role. The right to education is commonly seen as fundamental to the understanding and exercising of the whole set of 
human rights. This argument is put forward by Wringe (1986), who also emphasises the point that education in the contemporary world is essential for avoiding subjugation and exploitation by others. A similar position is put forward by Spring (2000), who sees education as an essential tool for minority groups such as indigenous peoples in successfully negotiating the challenges of globalisation. The first of Hodgson's (1998) justifications relating to public interest outlined above is instrumental in this way.

However, it is not clear from these discussions why the right to education should apply only to children, or only to particular forms of formal education. As discussed in McCowan (2010), the restriction of the absolute right to education to the 'elementary' level is justified neither on the basis of education's intrinsic and instrumental value, nor on the basis of positional advantages conferred. So, it is impossible to determine a particular level of literacy necessary for employment and recreation: very often as a person's skill and sensitivity in reading and writing develops through life, her work opportunities and engagement in cultural activities are progressively enhanced. It is quite arbitrary to determine that the learning provided in primary school is a right and at subsequent levels is simply a good. In relation to the autonomy proposed by Haydon, and to Curren's "initiation into practices that express human flourishing", it is hard to see how the development of these qualities has an end point -- they are not tasks that can be completed. Hodgson (1998) in fact acknowledges in relation to the justifications he puts forward that while children are the main beneficiaries, the right has a lifelong application. Any threshold of educational development established to mark the ending of the entitlement would be arbitrary.

Taking the positional aspect, a restriction of the absolute right to education to the primary level is also inadequate, particularly in light of the qualifications inflation that has rendered primary school leaving certificates almost worthless in the employment market in most countries. Of course, the positional dimension of education is complex from the perspective of universal rights given that we cannot universalise positional advantage, although we can guard against unfair disadvantage.

The right to education -- if it is a right at all -- must apply in some way throughout life. That is not to deny the importance of childhood as a phase of life in relation to education, and it is clear that the most intensive forms of education should occur in the stages of rapid development during childhood and adolescence. If it can be shown that some learning can only take place at particular phases of life, there may be justifications for compulsory education. Yet this is different from restricting the right to these phases. The right to education should not have a beginning and end point.

A second point about the general right to education is that purely instrumental views (e.g. Wringe 1986) cannot provide an adequate justification. If education is only seen as an effective means to achieving other valued functionings such as livelihoods or political participation, then it is not a right in itself; the rights are to livelihoods and political participation, with education merely a conduit. For it to be considered a right in itself, education must have some intrinsic value (although it can simultaneously have instrumental value). 
The right to higher education, therefore, should be seen in the context of a general right to education that runs through life. Higher education in this way is one of a number of options for organised learning available to people in adulthood, along with various forms of vocational education, job specific training, creative and artistic pursuits, personal development and so forth.

\section{Specific characteristics of a right to higher education}

However, it could be seen as insufficient to argue for a right to higher education purely on the basis of a right to lifelong education. It could rightly be asked whether there was anything in particular about higher education that gave it value. As argued by Barnett (1990: 6), higher education is not just "more of what has gone before", it indicates "a special level of personal development". Some elements can be seen as specific to the right to higher education, amongst the range of other educational options. The first and most prominent of these is that higher education -- in most societies -- provides unparalleled access to the best paid and most rewarding forms of employment. In part this stems from knowledge and skills gained (instrumental benefits), but also to the positional dimension of degree diplomas, imbued with divergent value in a hierarchical university system. As Brighouse states, the credential provides "enhanced competitiveness for the unequally distributed desirable positions and the unequally distributed goods that attach to them" (Brighouse forthcoming p.6).

Exclusion from these opportunities is clearly unjust and can be seen as an argument for a right to higher education. However, as stated above, this form of justification is not sufficient, as instrumental reasons on their own cannot form the basis of a right. (Conversely the phenomenon of graduate unemployment and other obstacles in converting higher education into opportunities in contemporary societies cannot be used as an argument against a right). One of the limitations of current academic debates on higher education is their often exclusive focus on this aspect. Bou-Habib (2010), for example, assesses arguments for and against state funding of higher education, concluding from a Rawlsian difference principle perspective that public subsidies are justifiable in so far as they promote the interests of the worst off in society. The author asserts that "we should not automatically assume that tax-funded higher education is a 'basic right' and neither should we assume that it is a privilege for which graduates alone should pay" (p.493). As pointed out by Kotzee and Martin (forthcoming), one problem with the account is that Bou-Habib (and others) address higher education purely in its 'external' role in achieving other social goods. In this sense alone, it may be that there is not a right to higher education -particularly as the advantages pointed to (primarily economic) could be provided by other means. Furthermore, if we primarily consider the positional benefits of $\mathrm{HE}$-and we assume that the higher education is necessarily positional in its benefits - then it becomes incoherent to assert a universal right (given that everyone cannot have positional advantage over everyone else). The positional benefits in fact are contingent on a restricted and unequal system, and would no longer apply in a universal and horizontal system. It is important, therefore, to consider not only the instrumental and positional benefits accrued from higher education study, but also its intrinsic value and students' experiences within the period of study. Like Kotzee and Martin (forthcoming), this article considers that it is the 
non-instrumental value of higher education -- the experience of learning, and the individual and collective process of intellectual development -- that people have a right to. Higher education is not the only means of engaging in this form of intellectual development, but it is an important one.

The intrinsic value of HE study can be understood in different ways. The acquisition of knowledge in specific fields can be seen to have intrinsic value, leading to an enhanced appreciation of, say, mathematical proofs, Islamic architecture or $14^{\text {th }}$ century poetry - an appreciation enabled by sustained and in-depth study of a type not normally possible in other forms of education. In a broader sense, we can see HE as providing initiation into a form of 'culture' in the Humboldtian sense of "the sum of all knowledge that is studied, as well as the cultivation and development of one's character as a result of that study" (Readings 1996: 15). Clearly, universities are guardians of just a part of what we would normally consider to be culture, but are no less valuable for that. In terms of widening participation, this aspect takes on particular importance, as certain groups in society have been marginalised historically on account of their restricted access to this store of culture. Furthermore, the deep enquiry and critical reflection enabled by HE study can be seen to have intrinsic value. This view is put forward by Nussbaum (1997: 30), drawing on the Stoics' idea that "higher education is a part of every human being's self-realisation" on account of its role in developing criticality.

There are of course a range of other instrumental benefits of HE study (see Bynner et al. 2003; McMahon 2009), not least of which is the development of political awareness and the ability to function as an informed and active citizen in a democratic society (Ahier, Beck \& Moore 2003; Arthur \& Bohlin 2005). Added to these is the enjoyment of the experience of HE study, the value of interaction with other students and staff, the making of friends and so forth.

$\mathrm{HE}$, therefore, has specific characteristics that provide a foundation for the right in addition to the characteristics shared with all education discussed in the previous section. There remain, however, some common objections to the assertion of a right to HE: four of these will be addressed in the sections that follow. The first is whether higher education -- as an often resource intensive and highly specialised activity, and one that has historically been restricted to the elites -- is in fact a privilege and not a right. The second is whether it is appropriate to assert a universal right to higher education given that not all people may have the capacity or desire to study at this level. Third, that movement towards a universal $\mathrm{HE}$ system leads to an intolerable degradation of quality; and fourth, that the right is unviable given the inability of states to fund universal access. The response provided here to these issues will in part be that the questions themselves are based on misunderstandings of and ambiguities in the idea of a right.

\section{A right or a privilege?}

"Education: a right, not a privilege!" can be found on placards in student protests around the world, from Santiago and Bogotá to London. The idea of education as a right has had enduring popular appeal around the world, particularly in contexts in which large 
proportions of the population are systematically excluded from education of adequate quality. The idea of higher education specifically as a right has also had significant rhetorical appeal among certain groups, especially as a response to the introduction of fees in public institutions. On the other hand, proponents of 'cost-sharing' for higher education have emphasised that university study is extremely expensive, that it benefits the few but is paid for through general taxation, and that it brings significant private advantages. In the latter sense, it is certainly a privilege for those people.

I will argue that both of these perspectives are valid, but that there is a use of the term 'right' that can to some extent accommodate itself to both. A good deal of the popular opposition to human rights generally speaking is based on concern that a rights culture encourages people to think about what they can 'get' rather than what they can 'give' to society. This criticism is based on a misunderstanding of the notion of human rights, in that accepting that a right pertains to all human beings entails extensive responsibilities in upholding that right for all others. While the increasingly individualistic nature of society and a lack of commitment to the welfare of others may be a valid concern, this trend is not one that can be identified with rights.

Concerns for a culture of 'getting' can certainly be observed in the sphere of higher education. Brighouse (forthcoming) and Brighouse and McAvoy (2009) provide a compelling account of higher education as a 'privilege', in the sense that in our unequal contemporary societies, advantaged groups have disproportionate access to prestigious university courses, which in turn can offer further positional advantage. The response to this situation - in the absence of a radically more equal social organisation - is that institutions and the students emerging from them should contribute much more to society, and its most disadvantaged members, that they currently do.

Higher education is certainly a privilege in this sense, and there are good reasons to believe that many students from advantaged backgrounds both take university study for granted and pay insufficient attention to their debt to the rest of society subsequently. It can be argued that this casualness with regard to the precious opportunity for higher education study is the fruit of a sense that it has in some way fallen into people's laps; there is stronger appreciation of educational opportunities in countries in which the right has been won through struggle in recent history.

Nevertheless, there is another sense of 'privilege' used in relation to higher education. The idea of privilege questioned by the Chilean students is one that is controlled and conferred by those in power, and may be conditional in particular ways. In this way, higher education has historically been a 'privilege', in the sense that it has only been available to particular segments of society (on the basis of gender, social class, racial/ethnic group etc.), or to a very tiny intellectual elite (i.e. a small proportion of those people with the capacity for higher education study). Elites have a vested interest in maintaining the restricted size of the university system, and given the prominent role of universities as sites of critique of government, there have also been disincentives for states to expand access to 'the masses', except in the form of demand-absorbing private institutions offering narrow vocational training. Of course, in this sense we are really talking about higher education being 'for the 
privileged', rather than being 'a privilege', but it is important to highlight this aspect since it is often the meaning attached to the term when contrasted with a right.

Higher education should be considered a right in the sense that it should be made available to all, but it should also be considered a privilege in the sense that it is a precious opportunity that must be taken advantage of as fully as possible and then used for the benefit of society. Nevertheless, being a right, its availability cannot be conditional on any particular use that it is subsequently put to, or indeed any previous performance (apart from adequate preparation). We may very much want students to go on to contribute to society after studying, and pay back their debt so to speak, and we may do our best to encourage them to do so, but they should be free to decide for themselves how to utilise the opportunity given. Yet as stated above, enjoying the right to higher education study entails upholding the right for all other members of society -- and indeed -- given that we are talking of a human right -- for all members of the human community.

\section{University for all?}

The second point relates to the proportion of the population that should study at university. Famously, the New Labour government in the UK set a goal of $50 \%$ of $18-30$ year-olds ${ }^{2}$. The arbitrariness of this figure is shown when it is disaggregated. In spite of the increase in the rates of young people going to university in recent years, the high proportion of the top socio-economic groups and low proportion of the bottom groups has changed little. UK government statistics (BIS 2011) show a very small improvement in the progression of students with free school meals (a proxy for socio-economic level), with the gap between these students and others still at 18 percentage points. Measures based on socio-economic class (BIS 2009) also show only a small improvement in the gap between the classes 1 to 3 and 4 to 7 in recent years ( $27.8 \%$ as opposed to $13.7 \%$ progression for 18 -year-olds). This phenomenon is evident around the world, with in some cases the proportion of lowerincome students actually going down in the context of expansion of the system. Any justification of the target of $50 \%$ on the basis that half of the population might have the desire and capacity to benefit from higher education is, therefore, clearly false (unless one considers that higher socio-economic groups have more inherent aptitude for higher education study). The places available in higher education in most countries correspond to perceived needs of the national economy, rather than any notion of learning interests of individuals.

Yet while most HE systems unfairly restrict the numbers of students entering, it is not necessarily the case in an ideal scenario that all people should study at university. The idea that $\mathrm{HE}$ is not suitable for all people could be proposed as an objection to a universal right. In fact, upholding higher education as a right is entirely consistent with recognising that not all people will want or be suitable to taking up the opportunity. Rights are freedoms and not obligations (although they will entail duties towards others). It is important that we protect the right to worship in society, even if only a tiny minority have any religious belief. A significant proportion of the population -- even with the opportunity of free-of-charge higher education study -- may decide not to take it up, or will opt for another form of

\footnotetext{
${ }^{2}$ Figures for higher education access are not always comparable between countries, as they include a range of different forms of study, not all of which would be considered higher education in all contexts.
} 
education. This proportion would be larger in a society in which university diplomas -independent of actual learning acquired - were not essential for most forms of well-paid employment: as Trow (2006) points out, in contemporary systems with near universal access, for the upper and middle classes higher education has become almost an 'obligation'.

However, individual desire to study is not the only factor that might justifiably restrict access -- there is also the question of selection procedures adopted by institutions and the system as a whole. The principal implication of higher education being a right is that no person should be unfairly barred from having access to it. The most obvious barriers are economic in nature, and if considered a right, university study should be either free or at such a low cost that it would not provide an obstacle to any segment of society. An associated point relating to fees is that higher quality provision should not carry a higher price - a characteristic of markets in most products, and one that is implied by the current reforms in the UK, and already seen in countries such as Brazil in which the process of privatisation is highly developed (McCowan 2004).

However, some entrance restrictions on the part of institutions are justified. A minimum level of academic preparation is necessary in order to gain meaningful access to the study made available in universities. (This article cannot address the question of which specific requirements there might be). Restrictions on entry to those who have this level of preparation are not justified by protection of academic standards relating to the institution, but by the interests of the individual students, who will be at best wasting their time by pursuing a course that they are not yet able to engage with. In conjunction with this, students should be able to return to higher education study at a later stage in life, and be supported in obtaining the necessary preparation. The forms of selection adopted must be criterion-referenced and not norm-referenced in the sense that the university system must be able to expand (and contract) in relation to the numbers of students wishing to study at that level and with the required level of capacity. There is no justification for a fixed number of places for which the highest performing students are selected.

A universal right to higher education does not, therefore, require, or even encourage, all people to attend university. It may well be that only a small proportion of the population will opt for it. Furthermore, a right to higher education is consistent with entry requirements that ensure the prospective students will be able to meaningfully engage with the course in question.

\section{Massification and quality}

One issue of relevance here is concern over quality of provision in the context of massification or universalisation of higher education. The question of the right to education inevitably involves quality, since we can only consider the right to have been realised if quality is of an acceptable level. There is little gain in ensuring access for $100 \%$ of the population to universities with inadequate provision for learning.

Concerns over quality are, therefore, entirely legitimate, and cannot be dismissed simply as entrenched elitism or belief in the inevitability of loss of standards when education is 
extended to all. Recent history has shown substantial problems of quality in the context of a rapid expansion of the university system, and in operating open access admission procedures. Some countries in continental Europe and Latin America, for example, have operated systems of entry that are not restrictive, and are controlled only by the possession of a secondary leaving certificate. While enabling greater enrolment, these systems have been characterised by overly large class sizes and very high rates of dropout. Argentina, for example, has a completion rate of less than $24 \%$ and Italy of approximately $45 \%$ (Altbach et al. 2009; European Commission 2010).

Trow's $(1974 ; 2006)$ well-known analysis of the movement from elite to mass and universal systems is of relevance here. There are problems that will naturally be faced in the transition of the higher education system, just as they have been faced in the universalisation of primary and secondary education (and are still being faced in most low and middle-income countries). These challenges stem from the rate of growth, changes to the absolute size of systems and institutions, and changes in the proportion of the relevant age group enrolled (Trow 1974). However, it is important to distinguish between problems of implementation and issues of principle. The argument put forward in this article is that there is a moral right to higher education, and not that there are no challenges in putting this vision into practice. The problems faced in countries such as Argentina and Italy are those of expanding enrolments and the size of institutions without sufficient allocation of resources, and not therefore problems inherent in the universalisation of higher education, any more than they are at primary and secondary levels.

Similar issues can be seen in relation to individual institutions. Rapid expansion or an open access system in a single university may well lead at least in the short term to a loss of quality or of a specific ethos that characterised it. In fact, a universal right to education does not necessarily mean expansion of existing institutions, but merely expansion of overall places which may involve a large number of small institutions -- if it is true that maintaining a small size can ensure a higher level of quality. What is clear, however, is that small institutions cannot unfairly restrict access to a specific portion of the population.

\section{Limits on available resources}

An obvious objection to an assertion of the right to education is lack of funds. Some of what might correspond to a right to higher education is of non-interference kind - i.e. being free to pursue one's intellectual development - but there is also a significant amount of provision that needs to be made by society. Clearly, the amount of time and resources that individuals and groups can call on from others in pursuing their educational interests is finite, and contingent on the particular conditions of a society at a particular point in time. Decisions have to be made in relation to the length of time it is justifiable for an individual to remain in higher education, and the distribution of resources between higher education and other educational options.

Yet we cannot veto a moral right to higher education on the basis that there are insufficient funds in the present moment. In a general sense, as argued by Sen (2004), we should not reign in our deliberation on rights by only considering what might now be practically possible in a particular country. The right to be free from murder or arbitrary imprisonment 
applies equally to people who happen to live in countries currently lacking the funds to support an adequate police force and legal system. When we think more specifically about higher education, current rates of expenditure on higher education students would indeed be hard for most societies to cope with for $100 \%$, or even $50 \%$, of the population. Yet as Bou-Habib (2010) argues, we cannot assume from the start an upper limit on expenditure on higher education, until we have discussed the demands of the various priorities that governments might have. This is particularly so in cases of countries in which the 'lack' of public funds to expand higher education systems has been caused or at least exacerbated by corruption, mismanagement and tax evasion. In addition, there may be a variety of forms of provision of higher education, not all of which are so resource intensive. To take some current examples, Cuba and Venezuela have achieved $95 \%$ and $78 \%$ gross enrolment rates ${ }^{3}$ respectively on moderate budgets (UIS 2011). Having said this, there will of course always be some limits on funds available, and - as is the case with the realisation of every human right - decisions have to be made in practice about where to employ and how to distribute resources.

\section{Conclusion}

This article has put forward two main arguments in response to the question posed.

1. Higher education is a right of all people, but only as one of a range of educational experiences available to adults.

2. Non-discriminatory access procedures are important, but not adequate in themselves; sufficient places must be available for all those desiring to study and with a minimum level of preparation.

In relation to the first point, it is recognised that general claims for education as a right are contested, given the difficulties common to all welfare rights in identifying the duty-bearer, in determining which forms of education might correspond to the right and whether these are universal orspecific to a given context. Yet if we uphold a general right to education it is arbitrary to create cut-off points (say 5-16); the entitlement must exist in some form throughout life. There is no implication in asserting the right that all or even most people should take it up, although there should be easy re-entry points so that people can choose to come to higher education at later stages in life.

This article considers that higher education as a right rests on the non-instrumental value of university study. In fact, as argued in McCowan (2010), while education has instrumental and positional value, it is only possible for there to be a right to education if there is some intrinsic value (otherwise the rights would be to the other goods -- e.g. viable livelihood, political participation -- with education just a means of supporting them). The extraordinary positional advantage conferred by a university degree is specific to our contemporary age, and yet the other benefits of university study pertain even when societies have developed other forms of sorting and selection. This article has focused on the question of access to higher education for students: in addition, it is important to remember that there are other forms of public interest in the university, and even possible rights pertaining, for example,

\footnotetext{
${ }^{3}$ The net rate for each age cohort would be lower.
} 
to the access of local communities to services provided, or the access of society as a whole to the knowledge developed.

The implications of this argument for policy are clear: HE systems as a whole need to expand, and furthermore elite institutions should either increase the number of places they offer, or if they wish to maintain their small size for educational reasons, should substantially democratise access. Tuition fees - other than small matriculation charges should not be charged. As argued above, higher education should be one of a range of options for post-school education available for the population, and occurring in formal institutions, but also in the workplace, trades unions, religious groups, social movements, political campaigns, community associations and so forth. Lawson's (1979) concern was that establishing higher education for all might place an intolerable burden on the curriculum, forcing it to diversify to the extent that it was no longer recognisable. In fact, this is not necessary if we retain the idea that higher education is only one of a range of options of adult education. Furthermore, a right to higher education does not necessarily imply access to an institution corresponding to our current 'university': it is but an institutional manifestation of higher learning that is dominant in the temporary age, while the sustained and in-depth enquiry characteristic of higher education can take place in other forms of setting.

There is also a time element to the question in that an 18-year-old may not choose to pursue $\mathrm{HE}$ (or be sufficiently equipped to undertake that study), yet the option should remain for entry at a later stage of life. (In fact, considerable progress in facilitating entry of 'mature' students has been made in many countries in recent years). Given the inequalities at the lower levels of the education system, substantial resources should be allocated to enabling people after leaving school to obtain the necessary preparation for entering higher education (in addition to addressing the inequalities at primary and secondary levels directly). Beyond access, ensuring a right to higher education would also involve a range of other considerations such as retention, quality of experience during study andsubsequent transitions. In fact, an adequate gauge of the fulfilment of the right to higher education would involve something along the lines of Tomasevski's (2006) 4 As scheme: that is, availability (existence of sufficient places), accessibility (non-discrimination in access to those places), acceptability (meaningful and respectful curriculum) and adaptability (institutional flexibility in accordance with student needs).

In relation to the second principle above, there has been considerable debate over questions of justice in university admissions. However, these debates have been predicated on the current situation of limited places in specific institutions that characterises HE in many (though not all) countries. A right to higher education would require the system to expand and contract in relation to the number of students desiring and able to study. In saying that higher education should be accessible to all on the basis of capacity, it should not be a competition in which the highest performing students get access to a limited number of places, but a requirement for fulfilling a minimal level of preparation. The ongoing debates over affirmative action policies in a number of countries, therefore, become immaterial: the meritocratic versus positive discrimination debate is predicated on an artificially restricted number of places. A just system would require there to be sufficient places for all who have the desire and ability for HE study. 
Even with universal access, there remain questions of diversity of institutions and potential disparities of prestige between them that would need to be addressed. Attention to nondiscrimination in the UDHR needs to be applied not only to access to the system as a whole, but to the institutions themselves, meaning that applicants should not be unfairly barred from accessing universities and courses of quality. This requirement would not preclude diversity in the system in terms of ethos, range of courses and other aspects, but it would entail consistently high quality across all institutions - i.e. horizontal rather than vertical differentiation (Brennan \& Naidoo 2008). As Brighouse (forthcoming) states, this task is highly challenging in contemporary societies given the entrenched inequalities stemming from educational experiences prior to university entry.

Students from wealthy backgrounds in our current unequal societies do not have a 'right' to higher education in the sense of obtaining added economic benefits at the expense of the general taxpayer, while access to low-income students is severely restricted. Yet engagement in meaningful educational experiences -- of which higher education is an example -- can indeed be seen as a right, one that should be upheld universally.

\section{References}

Ahier, J., Beck, J. and Moore, R. (2003) Graduate Citizens? Issues of Citizenship and Higher Education. London: RoutledgeFalmer.

Altbach, P., Reisberg, L. and Rumbley, L. (2009) Trends in Global Higher Education: Tracking an Academic Revolution. Paris: UNESCO.

Arthur, J. with Bohlin, K. (eds) (2005) Citizenship and Higher Education: The Role of Universities in Communities and Society. London: Routledge.

Barnett, R. (1990) The idea of higher education. Buckingham Open University Press.

Beiter, K. (2006) The protection of the right to education by international law. Leiden: Martinus Nijhoff.

BIS (2009) Full-time Young Participation by Socio-Economic Class (FYPSEC). 2009 Update. London: Department for Business, Innovation and Skills

BIS (2011) Widening participation in higher education: analysis of progression rates for young people in England by free school meal receipt and school type. London: Department for Business, Innovation and Skills

Bou-Habib, H. (2010). Who Should Pay for Higher Education? Journal of Philosophy of Education, 44 (4):479-495. 
Brennan, J. and Naidoo, R. (2008) Higher education and the achievement (and/or prevention) of equity and social justice. Higher Education. 56 (3): 287-302.

Brighouse, H. (forthcoming) Justice in Higher Education: An Odd View.

Brighouse, H. and McAvoy, P. (2009) Privilege, Wellbeing, and Participation in Higher Education. In Y. Raley and Preyer, G. (eds) Philosophy of education in the era of globalization. New York: Routledge.

Bynner, J., Dolton, P., Feinstein L., Makepiece, G., Malmberg, L. and Woods, L. (2003) Revisiting the Benefits of Higher Education: a Report by the Bedford Group for Lifecourse and Statistical Studies, Institute of Education. Bristol: HEFCE.

Curren, R. (2009) Education as a Social Right in a Diverse Society, Journal of Philosophy of Education, 43 (1), 45-56.

European Commission (2010) Efficiency and effectiveness of public expenditure on tertiary education in the EU. (European Economy Occasional Papers No 70). Brussels: Publications office of the European Union.

Haydon, G. (1977) The Right to Education and Compulsory Schooling, Educational Philosophy and Theory, 9 (1), 1-15.

Hodgson, D. (1998) The Human Right to Education. Dartmouth: Ashgate.

Kotzee, B. and Martin, C. (forthcoming) Who should go to university?

Maclntyre, A. (1990) Three Rival Versions of Moral Enquiry. London: Duckworth.

McCowan T (2004) The Growth of Private Higher Education in Brazil: Implications for Equity and Quality. Journal of Education Policy, 19 (4), 453-472.

McCowan, T. (2007) Expansion without equity: an analysis of current policy on access to higher education in Brazil. Higher Education, 53 (5), 579-598.

McCowan, T. (2010) Reframing the universal right to education. Comparative Education, 46 (4), 509-525.

McMahon, W. (2009) Higher Learning, Greater Good: The private and social benefits of higher education. Baltimore, MD: Johns Hopkins University Press.

Nussbaum, M. (1997) Cultivating humanity: A classical defense of reform in liberal education. Cambridge, Mass.: Harvard University Press.

Oakeshott, M. (1989) The idea of a university. In T. Fuller (ed.) The Voice of Liberal Learning: Michael Oakeshott on Education. New Haven and London: Yale University Press, pp. 95-104. 
Readings, B. (1996) The University in Ruins. Cambridge, MA: Harvard University Press.

Sen, A. (2004) Elements of a Theory of Human Rights. Philosophy and Public Affairs, 32 (4),315-356.

Sen, A. (2005) Human Rights and Capabilities. Journal of Human Development, 6 (2), 151-66.

Snook, I. and Lankshear, C. (1979). Education and Rights. Melbourne: Melbourne University Press.

Spring, J. (2000). The Universal Right to Education: Justification, Definition, and Guidelines New Jersey: Lawrence Erlbaum.

Tomasevski, K. (2006) Human rights obligations in education: the 4-A scheme. Nijmegen: Wolf Legal Publishers.

Trow, M. (1974) Problems in the Transition from Elite to Mass Higher Education. In OECD (ed.) Policies for Higher Education. Paris: OECD, 51-101.

Trow, M. (2006) Reflections on the transition from elite to mass to universal access: Forms and phases of higher education in modern societies since WWII. In J.J.F. Forest and P.G. Altbach (eds.) International Handbook of Higher Education. Dordrecht, The Netherlands: Springer. 243-280.

Wringe, C. (1986) The Human Right to Education. Educational Philosophy and Theory, 18 (2), $23-33$.

UNESCO Institute for Statistics (2011) Statistical tables. Available at http://stats.uis.unesco.org/unesco/TableViewer/tableView.aspx?Reportld=3345\&IF L anguage=eng (accessed 21/11/11)

Unterhalter, E. and Brighouse, H. (2007) Distribution of what for social justice in education? The case of Education for All by 2015. In M. Walker and E. Unterhalter (Eds) Amartya Sen's capability approach and social justice in education. New York: Palgrave Macmillan. 